\title{
Produtividade da cana-de-açúcar e teores residuais de nutrientes no solo após aplicações dejetos líquidos de suínos
}

\section{Productivity of sugarcane and residual nutrient content in the soil after pig slurry applications}

\section{June Faria Scherrer Menezes, Mariana Pina da Silva, Igor Muniz Neto, Vinicius de Melo Benites, Christian Luis Ferreira Bert}

Universidade de Rio Verde -UniRV, Fazenda Fontes do Saber, Campus Universitário Caixa Postal 104, Faculdade de Agronomia, CEP 75901-970, Rio Verde/GO. Email: june@unirv.edu.br

Resumo. Esse trabalho testou durante três anos consecutivos diferentes dosagens de dejetos líquidos de suínos (DLS) como fonte de adubação na cultura da cana-de-açúcar, e teve como propósito avaliar as produtividades e também os teores residuais de nutrientes no solo. O trabalho foi conduzido na Fazenda Fontes do Saber da Fesurv - Universidade de Rio Verde, em uma área que recebe dejetos líquidos de suínos desde a safra 2000/2001. Foram avaliados sete tratamentos (três repetições), sendo eles, controle (sem adubação mineral e orgânica), adubação mineral e doses crescentes de dejetos líquidos de suínos: $25 \mathrm{~m}^{3} \mathrm{ha}^{-1}, 50 \mathrm{~m}^{3} \mathrm{ha}^{-1}, 50 \mathrm{~m}^{3}$ ha${ }^{1}+\mathrm{N}, 100 \mathrm{~m}^{3} \mathrm{ha}^{-1}$ e $200 \mathrm{~m}^{3} \mathrm{ha}^{-1}$. Foram analisados a produtividade de cana-de-açúcar e os teores de fósforo, potássio, cobre e zinco residuais no solo. Não houve diferença estatística na produtividade da cana-de-açúcar em função dos tratamentos. Os dejetos líquidos de suínos podem ser utilizados na adubação da cana-de-açúcar, mas não como fonte de fósforo, pois os DLS não fornecem todo fósforo que a cultura demanda. O potássio é encontrado em grandes quantidades nos DLS, as recomendações de aplicação de dejetos no solo para adubação devem ter por base esse elemento. Após três anos de aplicações sucessivas de DLS os teores de cobre e zinco no solo não foram prejudiciais ao desenvolvimento da cultura da cana-de-açúcar.

Palavras chave: Saccharum officinarum L., resíduos orgânicos, química do solo, impacto ambiental.

Abstract. This study tested for three consecutive years different dosages of pig slurry (DLS) as a fertilizer source in the culture of sugarcane, and aimed to evaluate the productivity and also the residual levels of nutrients in the soil. The work was conducted in an area that receives pig slurry from the 2000/2001 harvest. Seven treatments (three replicates), namely, control (without mineral and organic fertilizer), mineral fertilizer and increasing doses of pig slurry: $25 \mathrm{~m}^{3} \mathrm{ha}^{-1}, 50 \mathrm{~m}^{3} \mathrm{ha}^{-1}, 50 \mathrm{~m}^{3} \mathrm{ha}^{-1}+\mathrm{N}, 100 \mathrm{~m}^{3} \mathrm{ha}^{-1}$ and $200 \mathrm{~m}^{3} \mathrm{ha}^{-1}$. We analyzed the productivity of sugarcane and phosphorus, potassium, copper and zinc in the waste soil. There was no statistical difference in the productivity of sugarcane in the treatments. The pig slurry can be used in the fertilization of sugarcane, but not as a source of phosphorus, for the DLS do not provide every match that culture demand. Potassium is found in large quantities in the DLS, the manure application recommendations in the soil for fertilization should be based on this element. After three years of successive applications of DLS copper and zinc contents in the soil were not detrimental to the development of the culture of sugarcane.

Key Words: Organic waste, Soil Chemistry, Environmental Impact.

\section{Introdução}

Lopes \& Caixeta Filho (1997) afirmam que dada à localização geográfica do estado de Goiás e sua proximidade a grandes centros consumidores, o mesmo possui grande vantagem no processamento e na produção de alimentos, aproveitando a produção de matéria-prima agropecuária.

São abatidos diariamente cerca de 5.000 suínos na região sudoeste de Goiás. Para a produção destes animais é gerada uma grande quantidade de resíduos, cerca de 12.000 a 13.000 


\section{(-)}

\section{Revista Agrarian}

ISSN: 1984-2538

$\mathrm{m}^{3}$ ano $^{-1}$ de dejetos de suínos, por lote de 3700 cabeças (Pohlmann et al. 2008).

Konzen (1983), afirma que dejeto suíno é constituído de fezes, urina, água desperdiçada dos bebedouros e na higienização, resíduos de ração, pêlos, poeiras e outros matérias decorrentes do processo criatório. Estes resíduos diluídos na água utilizada na higienização das baias e águas pluviais são denominados de dejetos líquidos de suínos (DLS).

Em relação à composição química, Perdomo, Lima \& Nones (2001) citaram que os dejetos suínos contêm matéria orgânica, nitrogênio, fósforo, potássio, cálcio, sódio, magnésio, ferro, zinco, cobre e outros elementos incluídos nas dietas dos animais. Oliveira (2001) afirma que parte desses nutrientes não é aproveitada pelos animais, que apresentam um baixo percentual de absorção desses nutrientes. Os suínos excretam na urina e nas fezes, $65 \%$ do $\mathrm{N}$, $75 \%$ do $\mathrm{P}$ e $80 \%$ de $\mathrm{K}$ consumidos.

Os dejetos de suínos podem ser usados na fertilização das lavouras, trazendo ganhos econômicos ao produtor rural, sem comprometer a qualidade do solo e do meio ambiente, se aplicados de forma adequada. Para isso, é fundamental a elaboração de um plano técnico de manejo e adubação, considerando a composição química dos dejetos, a área a ser utilizada, a fertilidade e tipo de solo e as exigências da cultura a ser implantada (Perdomo, Lima \& Nones, 2001).

Culturas como soja e milho já obtiveram resultados satisfatórios na utilização desse resíduo como fonte de adubação, outra cultura que vem sendo avaliada é na cana-de-açúcar.

A área plantada de cana-de-açúcar no Brasil cresceu consideravelmente, principalmente no centro-oeste, devido à demanda nacional e internacional por seus derivados.

$\mathrm{Na}$ cultura canavieira, a adubação representa até $40 \%$ do custo de produção e se destaca devido à grande produção e remoção de matéria verde por área plantada, necessitando reposição de nutrientes por meio de fertilizantes. $\mathrm{O}$ uso de dejetos líquido de suínos como fertilizante orgânico pode ser feito nesta cultura porque este contém uma série de elementos químicos prontamente disponíveis, ou que após o processo de mineralização estarão disponíveis e poderão ser absorvidos pelas plantas da mesma forma que aqueles oriundos de fertilizantes minerais industrializados (Diesel et al., 2002).

Com base nos fatores descritos, este trabalho teve como objetivos avaliar a produtividade da cana-de-açúcar e os teores residuais de alguns nutrientes no solo em função de diferentes dosagens de dejetos de suínos aplicados como fonte de nutrientes.

\section{Material e Métodos}

O trabalho foi conduzido na fazenda Fontes do Saber da UniRV - Universidade de Rio Verde, em uma área que recebe dejetos líquidos de suínos desde a safra 2000/2001, destinada ao projeto "Monitoramento do impacto ambiental pela utilização de dejetos líquidos de suínos na agricultura", em parceria com a UniRV/Embrapa e BRF.

A fazenda Fontes do Saber possui as coordenadas $17^{\circ} 48^{\prime}$ de latitude Sul e $55^{\circ} 55^{\prime}$ de longitude Oeste e encontra-se aproximadamente 760 metros de altitude.

Nesta área, a rotação de culturas utilizada anteriormente (safras de 2000 a 2006), se procedeu com as culturas de soja e milho, sendo que a aplicação de dejetos foi por aspersão, em área total, de maneira homogênea.

Este experimento com cana-de-açúcar foi conduzido nas safras 2006/2007, 2007/2008 e 2008/2009, utilizando-se o sistema de plantio convencional para a cultura, com a variedade RB845210, de ano e meio, com espaçamento entre linhas de $1,40 \mathrm{~m}$ e 18 a 20 gemas por metro.

Os tratamentos utilizados foram os seguintes: T1 (controle sem adubação); T2 $(500 \mathrm{~kg}$ $\mathrm{ha}^{-1}$ de adubo mineral NPK 04-30-16 + $100 \mathrm{~kg} \mathrm{ha}^{-}$ ${ }^{1}$ de $\mathrm{N}$ em cobertura); T3 (25 $\mathrm{m}^{3} \mathrm{ha}^{-1}$ de dejetos líquidos de suínos (DLS)); T4 $\left(50 \mathrm{~m}^{3} \mathrm{ha}^{-1} \mathrm{de}\right.$ dejetos líquidos de suínos); T5 $\left(50 \mathrm{~m}^{3} \mathrm{ha}^{-1} \mathrm{de}\right.$ dejetos líquidos de suínos $+100 \mathrm{~kg} \mathrm{ha}^{-1} \mathrm{de} \mathrm{N}$ em cobertura); T6 (100 $\mathrm{m}^{3} \mathrm{ha}^{-1}$ de dejetos líquidos de suínos) e T7 (200 m ha-1 de dejetos líquidos de suínos). A análises químicas dos dejetos de suínos (Rolas, 1995) utilizadas no período experimental encontram-se na Tabela 1. 


\section{Revista Agrarian}

ISSN: 1984-2538

Tabela 1. Quantidades médias e porcentagem de nutrientes nos dejetos utilizados no experimento.

\begin{tabular}{|c|c|c|c|c|}
\hline $\mathrm{N}$ & $\mathrm{P}_{2} \mathrm{O}_{5}$ & $\mathrm{~K}_{2} \mathrm{O}$ & $\mathrm{Cu}$ & $\mathrm{Zn}$ \\
\hline \multicolumn{3}{|c|}{ 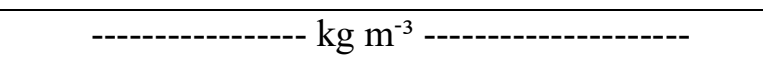 } & \multicolumn{2}{|c|}{---------- $\mathrm{g} \mathrm{m}^{-3}$---------- } \\
\hline 1,3 & 0,29 & 1,34 & 3,3 & 11,4 \\
\hline \multicolumn{5}{|c|}{------------------------------------- \% } \\
\hline 0,13 & 0,029 & 0,13 & 0,33 & 0,11 \\
\hline
\end{tabular}

Os tratamentos foram dispostos em delineamento experimental em blocos casualizados, com sete tratamentos e três repetições, totalizando, desta forma, vinte e uma parcelas experimentais. Cada parcela apresentava $20 \mathrm{~m}$ de comprimento e $10,80 \mathrm{~m}$ de largura, totalizando uma área total de $216 \mathrm{~m}^{2}$ e uma área útil, onde foram efetuados os cortes com finalidade de obter os dados experimentais, de $20 \mathrm{~m}^{2}$ sendo o restante da área composta pela bordadura.

A quantidade de adubo químico necessária foi calculada através de dados obtidos da análise química do solo do local onde o experimento foi conduzido (Tabela 2) seguindo metodologia descrita por Embrapa (1997), para atender as necessidades nutricionais da cultura da cana-deaçúcar.

Tabela 2. Resultado da análise química e textural do solo das parcelas destinadas à adubação convencional.

\begin{tabular}{|c|c|c|c|c|c|c|c|}
\hline $\mathrm{pH} \mathrm{CaCl}{ }_{2}$ & $\mathrm{Ca}$ & $\mathrm{Mg}$ & $\mathrm{K}$ & $\mathrm{Al}$ & $\mathrm{H}+\mathrm{Al}$ & CTC & $\mathrm{V}$ \\
\hline & \multicolumn{6}{|c|}{ - } & $\%$ \\
\hline 5,14 & 1,6 & 0,51 & 0,32 & 0,08 & 2,82 & 5,47 & 48,6 \\
\hline MO & Argila & Silte & Areia & $\mathrm{P}$ & K & $\mathrm{Cu}$ & $\mathrm{Zn}$ \\
\hline \multicolumn{4}{|c|}{ - } & \multicolumn{4}{|c|}{ - $\mathrm{mg} \mathrm{dm}^{-3}$} \\
\hline 10,4 & 650 & 90 & 260 & 1,06 & 126 & 3,8 & 2,1 \\
\hline
\end{tabular}

Os tratos culturais ocorreram conforme as necessidades da cultura, sendo que antes do plantio, procedeu-se a correção do solo da área experimental, utilizando-se calcário na dose de $2 \mathrm{t}$ ha $^{-1}$ segundo a metodologia para elevar o índice de saturação por bases do solo a $70 \%$ e PRNT de $58,5 \%$

Os dejetos foram provenientes de uma suinocultura SPL (Sistema de Produção de Leitões) de um integrado da BRF e permaneceram depositados na lagoa de estabilização da UniRV durante 30 dias para fermentação e estabilização.

As aplicações dos dejetos líquidos de suínos foram realizadas em setembro de cada ano e a adubação mineral por ocasião no plantio $\left(1^{\circ}\right.$ ano $)$ e as coberturas de $\mathrm{N}$ no segundo ano por ocasião da adubação com DLS.

Para o controle das plantas daninhas, foram feitas duas aplicações de herbicida, sendo a primeira com Ancosar (MSMA 2,0 L ha-1) + Metriméx $500 \mathrm{sc} \quad\left(4.0 \mathrm{~L} \mathrm{ha}^{-1}\right)+$ Advance (Hexazionone + Diuron 3,0 L ha' ${ }^{-1}$ Adjuvante) e a segunda com 2,4D (1,5 L ha $\left.\mathrm{h}^{-1}\right)+$ Sencor (Metribuzin 3,0 L ha-1 + MSMA 3,0 $\mathrm{L} \mathrm{ha}^{-1}$ ), de acordo com o histórico de plantas daninhas da área.

As colheitas da cana-de-açúcar foram realizadas na segunda quinzena do mês de setembro em todos os anos, 2006, 2007 e 2008.

Após o $3^{\circ}$ corte da cana-de-açúcar foram coletadas amostras de solo na profundidade de 0 $20 \mathrm{~cm}$ nas parcelas experimentais, com o objetivo de analisá-las quimicamente a fim de quantificar os teores residuais de nutrientes nos diferentes tratamentos. Analisaram-se os teores de $\mathrm{P}, \mathrm{K}, \mathrm{Cu}$ e Zn utilizando a solução extratora de Mehlich 1.

Os dados foram submetidos à análise de variância e as médias comparadas pelo teste de Tukey ( $\mathrm{p}>0,05)$. Utilizou-se o programa estatístico SAEG (Ribeiro Junior, 2001).

\section{Resultados e Discussão}

Ao analisar as quantidades de nutrientes adicionadas anualmente à cultura da cana-de- 


\section{Revista Agrarian}

ISSN: 1984-2538

açúcar em função das adubações verificou-se que a adubação mineral foi baseada na exigência nutricional da cana-de-açúcar e na análise do solo realizada por ocasião da instalação da cultura. Verificou-se que à medida que as doses de DLS foram aumentadas, obviamente aumentaram-se as quantidades de nutrientes (Tabela 3). Porém, a dose de $100 \mathrm{~m}^{3} \mathrm{ha}^{-1}$ de DLS foi equivalente à adubação mineral quanto ao nitrogênio com adição de $130 \mathrm{~kg} \mathrm{ha}^{-1}$ e $20+100 \mathrm{~kg} \mathrm{ha}^{-1}$, respectivamente (Tabela 3).

Quanto ao fósforo, nenhuma dose de DLS adicionou $\mathrm{P}_{2} \mathrm{O}_{5}$ equivalente à adubação mineral, faltando $\mathrm{P}$ ao sistema quando se aplicou apenas DLS (Tabela 3).

Tabela 3. Quantidades médias aplicadas de $\mathrm{N}, \mathrm{P}_{2} \mathrm{O}_{5}, \mathrm{~K}_{2} \mathrm{O}, \mathrm{Cu}$ e $\mathrm{Zn}$ conforme os tratamentos.

\begin{tabular}{lccccc}
\hline \multicolumn{1}{c}{ Tratamentos } & $\mathrm{N}$ & $\mathrm{P}_{2} \mathrm{O}_{5}$ & $\mathrm{~K}_{2} \mathrm{O}$ & $\mathrm{Cu}$ & $\mathrm{Zn}$ \\
\hline Testemunha & - & - & - & - & - \\
$25 \mathrm{~m}^{3} \mathrm{ha}^{-1}$ de DLS & 32,5 & 7,25 & 33,5 & 0,083 & 0,57 \\
$50 \mathrm{~m}^{3} \mathrm{ha}^{-1}$ de DLS & 65,0 & 14,5 & 67,0 & 0,165 & 1,14 \\
$50 \mathrm{~m}^{3} \mathrm{ha}^{-1}$ de DLS +N & 68,0 & 14,5 & 67,0 & 0,165 & 1,14 \\
$100 \mathrm{~m}^{3} \mathrm{ha}^{-1}$ de DLS & 130 & 29,0 & 134,0 & 0,330 & 2,28 \\
$200 \mathrm{~m}^{3} \mathrm{ha}^{-1}$ de DLS & 260 & 58,8 & 268,0 & 0,660 & 4,56 \\
$500 \mathrm{~kg} \mathrm{ha}^{-1}(04-30-16)$ & 20 & 150 & 80 & - & - \\
$+100 \mathrm{~kg} \mathrm{ha}^{-1}$ de N & & & & & \\
\hline
\end{tabular}

A dose de $50 \mathrm{~m}^{3} \mathrm{ha}^{-1}$ de DLS aproximou-se da adubação mineral quanto ao potássio adicionado no sistema. Consequente às doses de $100 \mathrm{~m}^{3} \mathrm{ha}^{-1} \mathrm{e}$ $200 \mathrm{~m}^{3} \mathrm{ha}^{-1}$ de DLS adicionaram $60 \%$ e $446 \%$ a mais de $\mathrm{K}$ necessário à cultura, o que provavelmente resultará em excesso deste nutriente no solo ao longo do tempo.

Tabela 4. Produção média e produção relativa da cana de açúcar dos tratamentos em relação à testemunha dos três cortes $(2007,2008$ e 2009).

\begin{tabular}{|c|c|c|c|c|c|c|c|}
\hline Tratamento & $\begin{array}{l}1^{\circ} \text { ano } \\
\text { t ha }^{-1} \\
2007\end{array}$ & $\begin{array}{c}\text { Produção } \\
\text { relativa } \\
(\%)\end{array}$ & $\begin{array}{l}2^{\circ} \text { ano } \\
\text { t ha }^{-1} \\
2008\end{array}$ & $\begin{array}{c}\text { Produção } \\
\text { relativa } \\
(\%)\end{array}$ & $\begin{array}{l}3^{\circ} \text { ano } \\
\text { t ha }^{-1} \\
2009\end{array}$ & $\begin{array}{c}\text { Produção } \\
\text { relativa } \\
(\%)\end{array}$ & $\begin{array}{c}\text { Produçã } \\
\text { o média } \\
(3 \text { anos }) \\
t_{\text {ha }}{ }^{-1}\end{array}$ \\
\hline Testemunha & 79,29 & 100,00 & 69,17 & 100,00 & 65,25 & 100,00 & 71,24 \\
\hline $25 \mathrm{~m}^{3} \mathrm{ha}^{-1}$ de DLS & 94,13 & 118,72 & 68,96 & 99,67 & 73,73 & 113,00 & 78,94 \\
\hline $50 \mathrm{~m}^{3} \mathrm{ha}^{-1}$ de DLS & 83,65 & 105,50 & 50,21 & 72,59 & 96,67 & 148,15 & 76,84 \\
\hline $50 \mathrm{~m}^{3} \mathrm{ha}^{-1} \mathrm{de}$ DLS $+\mathrm{N}$ & 82,07 & 103,51 & 87,63 & 126,68 & 73,10 & 112,03 & 80,93 \\
\hline $100 \mathrm{~m}^{3} \mathrm{ha}^{-1}$ de DLS & 93,73 & 118,21 & 78,54 & 104,87 & 79,87 & 122,41 & 84,05 \\
\hline $200 \mathrm{~m}^{3} \mathrm{ha}^{-1}$ de DLS & 89,21 & 112,51 & 78,69 & 113,76 & 78,86 & 120,86 & 82,25 \\
\hline $\begin{array}{l}500 \mathrm{~kg} \mathrm{ha}^{-1}(04-30-16) \\
+100 \mathrm{~kg} \mathrm{ha}^{-1} \mathrm{de} \mathrm{N}^{-10}\end{array}$ & 92,54 & 116,71 & 93,89 & 135,74 & 53,55 & 82,07 & 80,00 \\
\hline Média & 87,80 & & 75,30 & & 74,41 & & 79,18 \\
\hline CV (\%) & 17,44 & & 24,48 & & 27,31 & & 22,38 \\
\hline
\end{tabular}

\begin{abstract}
A produtividade de colmos obtida com o
ratamento mineral no primeiro corte foi $16,71 \%$
A produtividade de colmos obtida com o
tratamento mineral no primeiro corte foi $16,71 \%$ superior à testemunha e $2,01 \%$ inferior a produtividade do tratamento com $25 \mathrm{~m}^{3} \mathrm{ha}^{-1} \mathrm{de}$
\end{abstract}

Avaliando-se as produtividades da canade-açúcar em função das adubações (Tabela 4), observou-se que houve acréscimo da produtividade dos tratamentos que receberam os dejetos líquidos de suínos, em relação à testemunha. dejetos. Os tratamentos com 25 e $100 \mathrm{~m}^{3} \mathrm{ha}^{-1}$ de DLS foram mais produtivos em relação à testemunha e a adubação mineral com $18,72 \%$ e $18,21 \%$ respectivamente. 


\section{(a) \\ Revista Agrarian \\ ISSN: 1984-2538}

No segundo corte, a adubação mineral foi $35,74 \%$ superior à testemunha, a adubação com 50 $\mathrm{m}^{3}$ de DLS $+\mathrm{N}$ proporcionou aumento de produtividade nas parcelas que receberam DLS, sendo $26,68 \%$ mais que a testemunha em que não houve adição de adubo mineral e 9,06\% menos produtiva que a adubação mineral (Tabela 4). No terceiro corte, o tratamento que mais se destacou foi o que recebeu $50 \mathrm{~m}^{3}$ ha-1 de DLS, $48,15 \%$ a mais em relação à testemunha (Tabela 4).

No primeiro corte as parcelas que foram adubadas com DLS nas doses de $25 \mathrm{e} 100 \mathrm{~m}^{3}$ ha $^{-1}$ superaram a adubação mineral na produtividade, em 1,72 e 1,28\%, respectivamente
(Tabela 5). Observou-se que no segundo corte as produtividades relativas da cana-de-açúcar adubadas com DLS foram inferiores as parcelas fertilizadas com adubo mineral, sendo a mais produtiva entre as parcelas adubadas com DLS, o tratamento que recebeu $50 \mathrm{~m}^{3} \mathrm{ha}^{-1}+\mathrm{N}$, esse tratamento foi $6,67 \%$ inferior ao tratamento que recebeu a adubação mineral (Tabela 5).

As produtividades relativas obtidas no terceiro corte, da cana-de-açúcar nas parcelas que receberam DLS foram todas superiores a adubação mineral, sendo que a dose de $50 \mathrm{~m}^{3} \mathrm{ha}^{-1}$ de DLS a que obteve maior produção, correspondente a $180,52 \%\left(96,67 \mathrm{t} \mathrm{ha}^{-1}\right)$ (Tabela 5).

Tabela 5. Produção média e produção relativa da cana de açúcar nos tratamentos com DLS comparadas com o tratamento mineral dos três cortes $(2007,2008$ e 2009).

\begin{tabular}{lccccccc}
\hline Tratamento & $\begin{array}{c}1^{\circ} \text { ano } \\
\mathrm{t} \mathrm{ha}^{-1} \\
2007\end{array}$ & $\begin{array}{c}\text { Produção } \\
\text { relativa } \\
(\%)\end{array}$ & $\begin{array}{c}2^{\circ} \text { ano } \\
\mathrm{tha}^{-1} \\
2008\end{array}$ & $\begin{array}{c}\text { Produção } \\
\text { relativa } \\
(\%)\end{array}$ & $\begin{array}{c}3^{\circ} \text { ano } \\
\mathrm{t} \mathrm{ha}^{-1} \\
2009\end{array}$ & $\begin{array}{c}\text { Produção } \\
\text { relativa } \\
(\%)\end{array}$ & $\begin{array}{c}\text { Produção } \\
\text { média } \\
(3 \text { anos }) \\
\text { ha }^{-1}\end{array}$ \\
\hline $25 \mathrm{~m}^{3} \mathrm{ha}^{-1}$ de DLS & 94,13 & 101,72 & 68,96 & 73,45 & 73,73 & 137,68 & 78,94 \\
$50 \mathrm{~m}^{3} \mathrm{ha}^{-1}$ de DLS & 83,65 & 90,39 & 50,21 & 53,48 & 96,67 & 180,52 & 76,84 \\
$50 \mathrm{~m} \mathrm{ha}^{3} \mathrm{ha}^{-1}$ de DS +N & 82,07 & 88,68 & 87,63 & 93,33 & 73,10 & 136,50 & 80,93 \\
$100 \mathrm{~m} \mathrm{~m}^{3} \mathrm{ha}^{-1}$ de DLS & 93,73 & 101,28 & 78,54 & 83,65 & 79,87 & 147,29 & 84,05 \\
$200 \mathrm{~m}^{3} \mathrm{ha}^{-1}$ de DLS & 89,21 & 96,40 & 78,69 & 83,81 & 78,86 & 147,26 & 82,25 \\
$500 \mathrm{~kg} \mathrm{ha}^{-1}(04-30-$ & 92,54 & 100 & 93,89 & 100 & 53,55 & 100 & 80,00 \\
$16)+100 \mathrm{~kg} \mathrm{ha}^{-1}$ de N & & & & & & & \\
\hline Média & 87,80 & & 75,30 & & 74,41 & & 79,18 \\
\hline $\mathrm{CV}(\%)$ & 17,44 & & 24,48 & & 27,31 & & 22,38 \\
\hline
\end{tabular}

Os resultados na produtividade indicam que os dejetos líquidos de suínos podem ser usados na adubação da cana-de-açúcar sem redução de produtividade, podendo até elevá-la. Porém, a adubação mineral fornece todos os nutrientes de forma equilibrada e disponível para a planta, o DLS possui algumas limitações nesses sentidos, principalmente em relação ao equilíbrio dos nutrientes, isso ocorre por diversos fatores, sendo o principal a alimentação fornecida aos suínos.

Konzen et al. (1998), pesquisando a utilização do esterco líquido de suínos na adubação de milho, utilizaram diversas doses em aplicações exclusivas e combinadas com adubação mineral. A aplicação uniforme de 45, 90, 135 e $180 \mathrm{~m}^{3} \mathrm{ha}^{-1} \mathrm{de}$ dejetos de suínos promoveu acréscimos de 48 a
$119 \%$ na produtividade, em relação ao uso unicamente de adubação mineral, que proporcionou produtividade de $3.490 \mathrm{~kg} \mathrm{ha}^{-1}$. A produtividade da testemunha, sem adubação, foi de $1.600 \mathrm{~kg} \mathrm{ha}^{-1}$.

Oliveira (2000) estudou a disposição de lodo de esgoto em Latossolo Vermelho-amarelo cultivado com cana-de-açúcar no segundo corte, nas dosagens de 37, 74 e $110 \mathrm{t} \mathrm{ha}^{-1}$ de lodo de esgoto. A produtividade agrícola média para essas dosagens foi $33 \%$ superior que a da testemunha, que foi de $101 \mathrm{tha}^{-1}$.

Observou-se que os dejetos líquidos de suínos possuem altas quantidades de $\mathrm{K}$, e que essas quantidades deixaram altos residuais de $\mathrm{K}$ no solo (Figura 1). 


\section{Revista Agrarian}

ISSN: 1984-2538

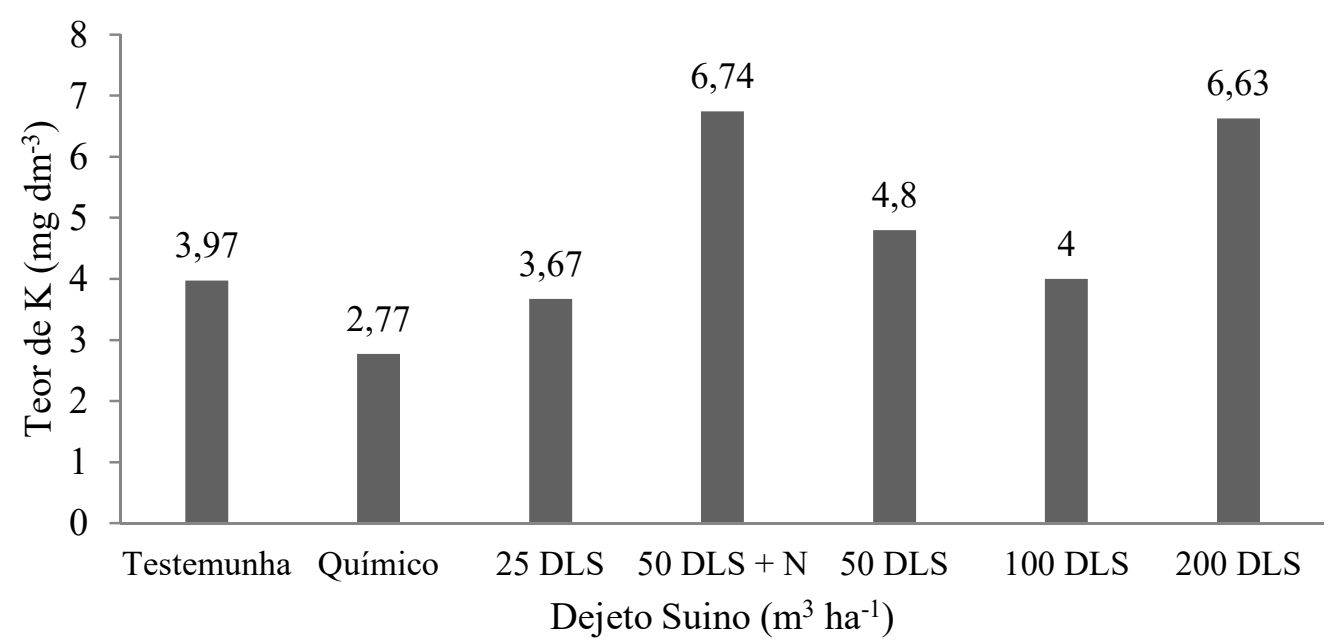

Figura 1. Teores residuais de $\mathrm{K}$ no solo em função de diferentes adubações na cultura da cana de açúcar após três anos de aplicações sucessivas de DLS.

Não houve diferença entre os tratamentos para as diferentes dosagens de $\mathrm{K}$, no entanto observando a Figura 1 notou-se que ocorreu um aumento dos teores residuais do elemento no solo, conforme aumentava a dosagem. O aumento foi de $130 \%$ do tratamento que recebeu $200 \mathrm{~m}^{3} \mathrm{ha}^{-1}$ de DLS em relação à testemunha e $26 \%$ superior ao tratamento mineral que recebeu $80 \mathrm{~kg} \mathrm{ha}^{-1}$ de $\mathrm{K}_{2} \mathrm{O}$.

Assmann et al. (2007), afirmam que com a aplicação de DLS nas doses de 20, 40 e $80 \mathrm{~m}^{3} \mathrm{ha}^{-1}$ de DLS, observaram aumentos nos teores de K na camada superficial do solo. Chateaubriand (1988), corroboram com os encontrados por Assmann et al. (2007), em que aplicando doses de 0 a $200 \mathrm{~m}^{3} \mathrm{ha}^{-1}$ de DLS observaram aumentos na concentração de $\mathrm{K}$ disponível no solo, na mesma profundidade.

$\mathrm{O}$ tratamento que deixou maior residual de $\mathrm{P}$ no solo foi o tratamento que recebeu adubação química, isso se deve ao fato do elemento ser aplicado de forma superestimada, devido seu baixo aproveitamento pela cultura por ser um elemento de baixa mobilidade no solo e ter grande parte fixada aos colóides do solo (Figura 2).

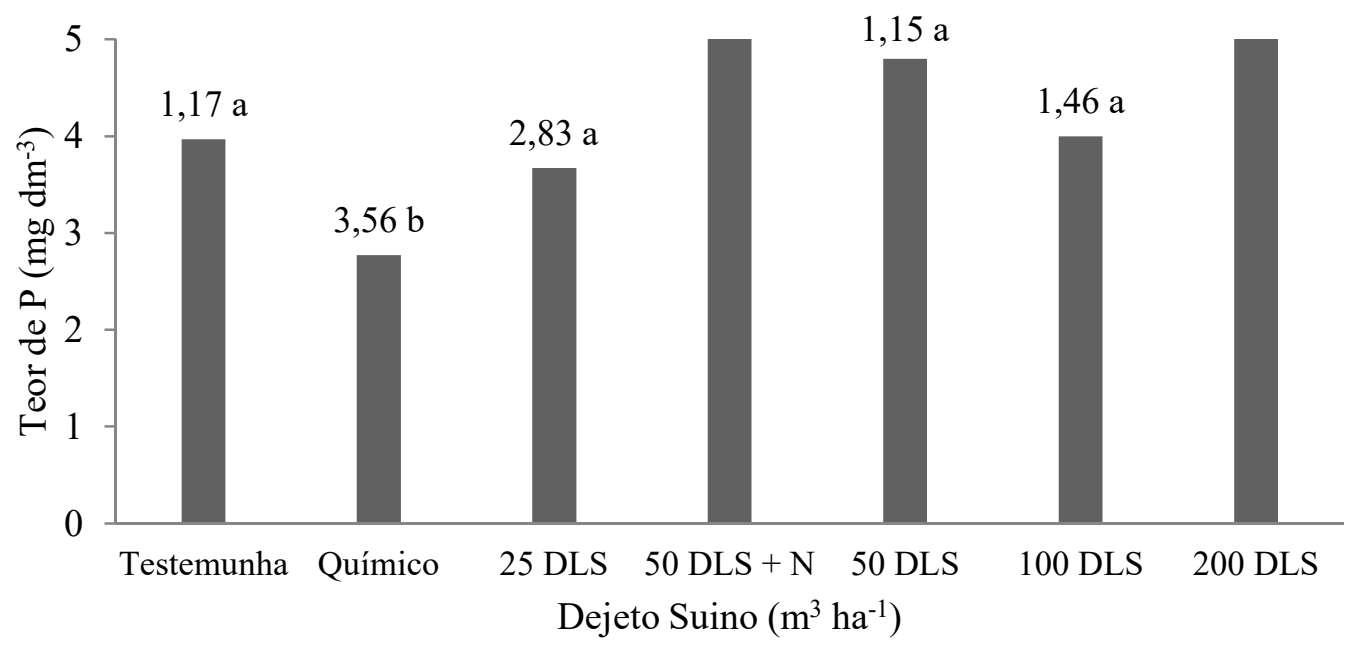

Figura 2. Teores residuais de $\mathrm{P}$ no solo em função de diferentes adubações na cultura da cana de açúcar após três anos de aplicações sucessivas de DLS. Médias seguidas da mesma letra minúscula não diferem entre si pelo teste de tukey ao nível de 5\% de probabilidade 


\section{(2) \\ Revista Agrarian \\ ISSN: 1984-2538}

Mesmo quando fertilizantes são aplicados, a maior parte do $\mathrm{P}$ adicionado é adsorvida em colóides do solo, tornando-se com tempo não disponível, dada a formação de compostos de baixa solubilidade, sem propiciar uma adequada contribuição a produção vegetal (Araujo \& Machado, 2006).

Os tratamentos que receberam dejetos líquidos de suínos apresentaram teores residuais de $\mathrm{P}$ no solo inferiores ao tratamento mineral, pois as quantidades de $\mathrm{P}$ aplicadas via dejetos não atendem as exigências nutricionais completa da cultura. $\mathrm{Ou}$ seja, para fornecer todo o P via dejetos iria ocorrer um desequilíbrio de outros elementos, correndo o risco de causar prejuízos à cultura de imediato ou em anos posteriores. Por isso, recomenda-se a adubação complementar de $\mathrm{P}$ utilizando-se outras fontes de fertilizante mineral contendo $\mathrm{P}$ juntamente com a aplicação de DLS.

As doses recomendadas de $\mathrm{P}_{2} \mathrm{O}_{5}$ para cana planta variam de 40 a $50 \mathrm{~kg}$ por hectare dependendo da produtividade esperada. Os DLS não conseguem suprir essas quantidades (Tabela 3), devido à baixa quantidade desse elemento em sua composição.

Souza \& Lobato (2002) ao compararem os teores de $\mathrm{P}$ no solo em função das adubações, verificaram que, os teores médios de $\mathrm{P}$ obtidos da adubação mineral foram estatisticamente superiores aos demais tratamentos. Com a adubação mineral, na camada de 0 a $10 \mathrm{~cm}$, obtevese teor adequado de $\mathrm{P}$ no solo, correspondente a $12,07 \mathrm{mg} \mathrm{dm}^{-3}$.

Os teores residuais de $\mathrm{Cu}$ no solo mostraram-se superiores nos tratamentos que receberam DLS. A maior concentraçao desse elemento foi observada no tratamento que recebeu $200 \mathrm{~m}^{3}$ ha ${ }^{-1}$ de DLS, esse tratamento em relação a testemunha obteve um acréscimo de $33,4 \%$ (Figura 3). As maiores doses de DLS apresentaram os maiores teores de $\mathrm{Cu}$ no solo do que os solos da testemunha e da adubaçao mineral, pois nesses tratamentos não foram adicionados cobre.

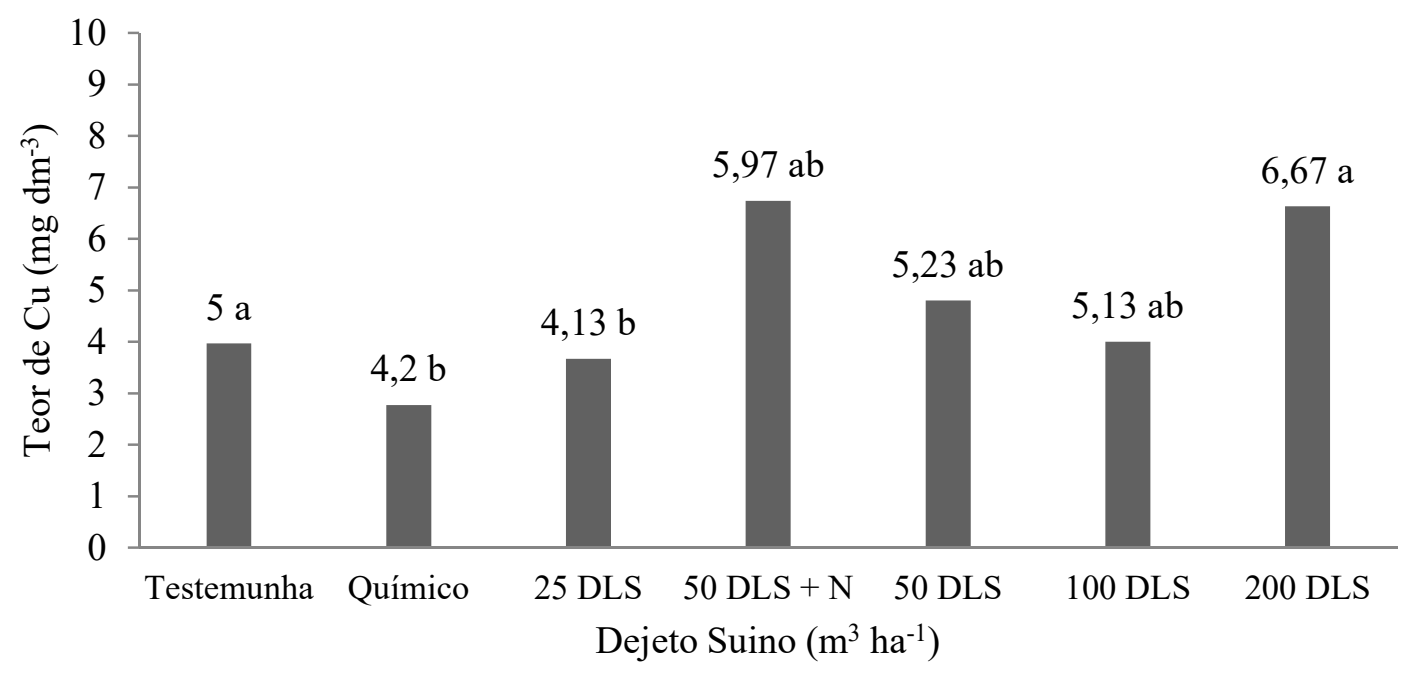

Figura 3. Teores residuais de $\mathrm{Cu}$ no solo em função de diferentes adubações na cultura da cana de açúcar após três anos de aplicações sucessivas de DLS. Médias seguidas da mesma letra minúscula não diferem entre si pelo teste de tukey ao nível de $5 \%$ de probabilidade

A adubação de manutenção com cobre recomendada para a cultura da cana-de-açúcar é de $3,0 \mathrm{~kg} \mathrm{ha}^{-1} \mathrm{de} \mathrm{Cu}$ (Sousa \& Lobato, 2002) e valores acima de $65 \mathrm{mg} \mathrm{dm}^{-3}$ de $\mathrm{Cu}$ é considerado fitotóxico, o que poderá causar queda de produtividade da cultura (Melo et al., 2000). E se os teores forem superiores a $1500 \mathrm{mg} \mathrm{dm}^{-3}$ são indicados como o máximo permitido pela Cetesb (1999). Como os valores determinados de $\mathrm{Cu}$ no solo neste trabalho estavam abaixo dos teores indicativos de contaminação, pode-se inferir que os teores residuais de $\mathrm{Cu}$ no solo não limitaram a produtividade da cana-de-açúcar. 


\section{(2) \\ Revista Agrarian \\ ISSN: 1984-2538}

De acordo com Vieira (1997), metais pesados como $\mathrm{Zn}$ e $\mathrm{Cu}$ podem ser acumulados no solo em níveis tóxicos, principalmente quando o pH é inferior a 6. Estudos efetuados em Taiwan na cultura de cana-de-açúcar irrigada com efluentes de suinocultura, encontraram níveis de metal no solo, em $\mathrm{mg} \mathrm{kg}^{-1}$, variando de 3,07 a 8,22 para o $\mathrm{Cu} ; 2,89$ a 9,14 para o $\mathrm{Zn}$. Baseados nestes resultados, os autores concluíram que não houve limitação para o desenvolvimento da cana-de-açúcar com esses teores de metais pesados.

Os residuais de teores de zinco no solo foram maiores nos tratamentos que recebram dejetos de suinos, com os maiores teores nos tratamentos com $50 \mathrm{~m}^{3}$ e $200 \mathrm{~m}^{3} \mathrm{ha}^{-1}$ de DLS, que foram $69,8 \%$ e $67,0 \%$ superiores a testemunha (Figura 4).

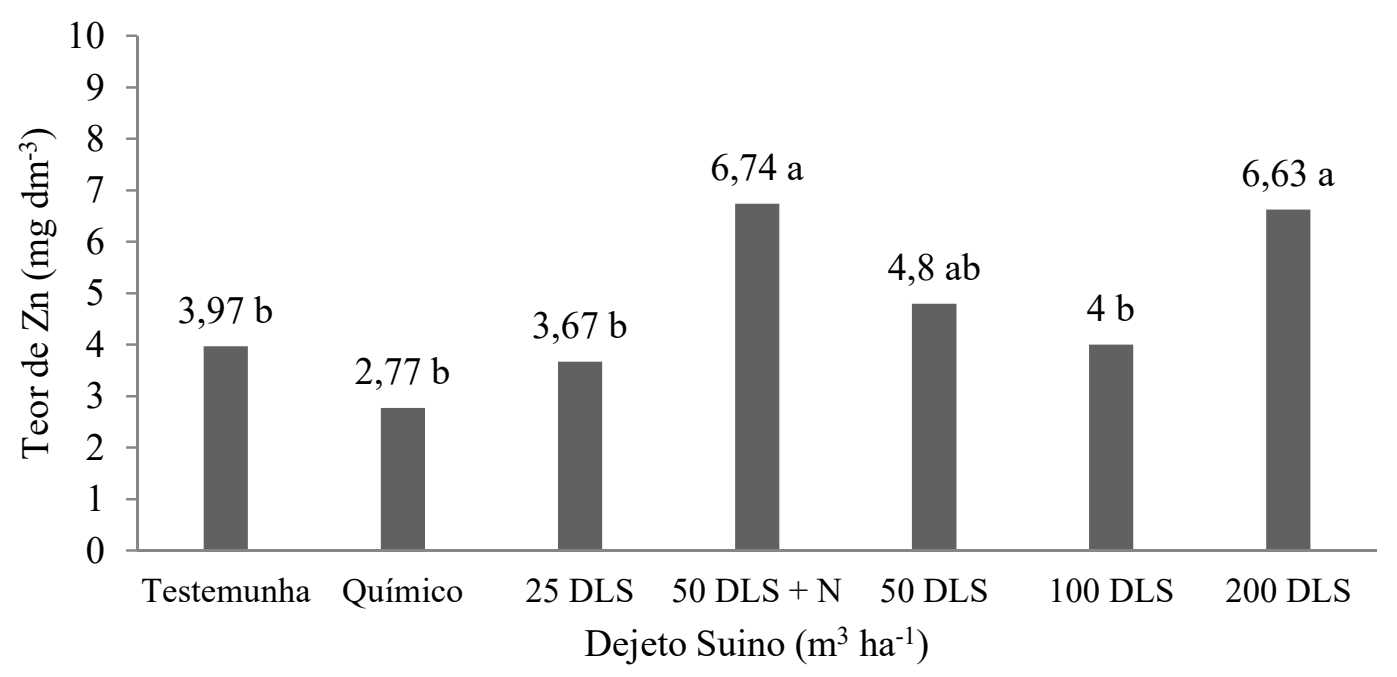

Figura 4. Teores residuais de $\mathrm{Zn}$ no solo em função de diferentes adubações na cultura da cana de açúcar após três anos de aplicações sucessivas de DLS. Médias seguidas da mesma letra minúscula não diferem entre si pelo teste de tukey ao nível de 5\% de probabilidade.

Dos micronutrientes, o $\mathrm{Zn}$ é o mais provável de tornar-se tóxico porque é utilizado em grandes quantidades na ração de leitões $(2.400 \mathrm{mg}$ $\mathrm{kg}^{-1}$ ) com o objetivo de eliminar os distúrbios gastrointestinais provocados pelo desmame (Menten et al., 1992). Grande parte desse Zn não é absorvida pelos animais, sendo eliminada nas fezes (Cristani, 1997).

L'herroux et al. (1997), após cinco anos com aplicação de dejetos de suínos, encontraram aumentos nos teores de $\mathrm{Cu}$ e $\mathrm{Zn}$ no solo e movimentação destes no perfil do solo. Contudo, o acúmulo em áreas agrícolas onde se faz o uso de dejetos de suínos como fonte de nutrientes, nem sempre é detectado, como o observado por Mattias (2006).

Neste experimento os teores de zinco não foram limitantes para a cultura da cana-de-açúcar, o teor considerado tóxico desse elemento no solo é $2400 \mathrm{mg} \mathrm{dm}^{-3}$ de $\mathrm{Zn}$ (Cetesb, 1999), e a dose recomendada para a adubação da cultura é de 6,0 $\mathrm{kg} \mathrm{ha}^{-1}$ de $\mathrm{Zn}$, logo o zinco não foi prejudicial a cultura e não apresenta-se como contaminante do solo.

\section{Conclusões}

Os dejetos líquidos de suínos podem substituir parcialmente a adubação da cana-deaçúcar.

Os teores residuais de cobre e zinco no solo proveniente dos DLS durante os três anos de experimento não foram limitantes para o desenvolvimento da cultura da cana-de-açúcar.

\section{Referências}

ARAUJO, A.P; MACHADO, C. T. Fósforo. In Fernandes, M.S.(ed.) Nutrição Mineral de plnatas, SBCS, Viçosa, 2006. 432p.

ASSMANN, T. S.; ASSMANN, A. L.; SOARES, A. B.; CASSOL, L. C.; GIASSON, M. S.; GIASSON, N. F. Fixação biológica de nitrogênio 


\section{(a) \\ Revista Agrarian \\ ISSN: 1984-2538}

por plantas de trevo (Trifolium spp.) em sistema de integração lavoura-pecuária no Sul do Brasil. Revista Brasileira de Zootecnia,

CETESB. Aplicação de lodos de sistemas de tratamento biológico em áreas agrícolas - Critérios para projeto e aplicação. São Paulo, 1999. Manual Técnico. 32p. (P. 4230, agosto de 1999).

CHATEAUBRIAND, A.D. Efeito de esterco líquido de suínos aplicados em irrigação por sulcos, na cultura do milho (Zea mays L.). Viçosa, MG, Universidade Federal de Viçosa, 1988. 61p. (Tese de Mestrado).

CRISTANI, J. Efeito do óxido de zinco (ZnO) no controle da diarréia pós-desmame em leitões experimentalmente desafiados com Escherichia coli. Pelotas, Universidade Federal de Pelotas, 1997. 74p. (Tese de Mestrado)

DIESEL, R.; MIRANDA, C.R.; PERDOMO, C.C. Coletânea de tecnologias sobre dejetos suínos. Boletim Informativo de Pesquisa - Embrapa Suínos e Aves e Extensão - EMATER/RS. Ano 10, n.14, 2002.

EMBRAPA. Centro Nacional de Pesquisa de Solos (Rio de Janeiro, RJ). Manual de métodos de análise de solo. 2. ed. rev. atual. Rio de Janeiro, 1997. $212 \mathrm{p}$.

KONZEN, E. A.; PEREIRA FILHO, I. A.; BAHIA FILHO, A. F. C.; PEREIRA, F. A. Manejo do esterco líquido de suínos e sua utilização na adubação do milho. 2.ed. Sete Lagoas : EMBRAPA-CNPMS, 1998. 31p. (EMBRAPA, Circular Técnica, 25).

KONZEN, E.A. Manejo e utilização de dejetos suínos. Concórdia: Embrapa - CNPSA, 1983. 32p. EMBRAPA. (Circular Técnica, 6).

L'HERROUX, L., LE ROUX, S., APPRIOU, P., MARTÍNEZ, J. Behaviour of metals following intensive pig slurry applications to a natural field treatment process in Brittany (France). Environmental Pollution, v. 97, n.1-2, p.119-130, 1997.

LOPES, R. L., CAIXETA FILHO, J. V. Logística de localização aplicada à suinocultura: um estudo para o estado de Goiás. Preços Agrícolas, Ano XI, n. 133, p. 19-25, nov. 1997.

MATTIAS, J. L. Metais pesados em solos sob aplicação de dejetos líquidos de suínos em duas microbacias hidrográficas de Santa Catarina. 2006. 165 f. Tese (Doutorado em Ciência do Solo). Universidade Federal de Santa Maria, Santa Maria, 2006.

MELO, W. J. de M.; MARQUES, M. O.; MELO, V. P. de; CINTRA, A. A. D. Uso de resíduos em hortaliças e impacto ambiental. Revista Brasileira de Horticultura. Jaboticabal: UNESP. 2000.

MELO, W. J. de M.; MARQUES, M. O.; MELO, V. P. de; CINTRA, A. A. D. Uso de resíduos em hortaliças e impacto ambiental. Revista Brasileira de Horticultura. Jaboticabal: UNESP. 2000.

MENTEN, J.F.M.; MIYANDA, V.S.; CITRONI, A.R. Suplementação de alto nível de zinco na dieta de leitões. In: REUNIÃO ANUAL DA SOCIEDADE BRASILEIRA DE ZOOTECNIA, Lavras, 1992. Anais... Lavras, Sociedade Brasileira de Zootecnia, 199p.368.

OLIVEIRA, F. C. Disposição de lodo de esgoto e composto de lixo urbano num latossolo vermelho-amarelo cultivado com cana-deaçúcar. 2000. $247 \mathrm{f}$. Tese (Doutorado) - Escola Superior de Agricultura de Luiz de Queiroz, Piracicaba, 2000.

OLIVEIRA, P.A.V. Sistema de produção de suínos em cama sobreposta. In: SEMINARIO NACIONAL DE DESENVOLVIMENTO DA SUINOCULTURA, 9,2001, Gramado. Anais... Concórdia: Embrapa Suinos e Aves, 2001. P44-55.

PERDOMO, C.C.; LIMA DE, M.M.J.G.; NONES, K.; Produção de suínos e meio ambiente: In: SEMINARIO NACIONAL DE DESENVOLVIMENTO DA SUINOCULTURA, 9, 2001, Gramado, RS. Anais... Concórdia: Embrapa Suinos e Aves, 2001. P.8-24.

POHLMANN, R. A. de C.; SCHWERTZ, M.; PAULINO, H. B. Perfil agroindustrial da região sudoeste do estado de Goiás: potencialidades de poluição. In: I CONGRESSO GOIANO DE EDUCAÇÃO AMBIENTAL, 2008, Goiânia, GO. Anais... Goiânia, 2008.

RIBEIRO JUNIOR, J.I. Análises Estatísticas no SAEG. UFV. Viçosa, 2001.301p.

ROLAS - Recomendações de adubação e calagem para os Estados do Rio Grande do Sul 


\section{Revista Agrarian}

ISSN: 1984-2538

e Santa Catarina. Passo Fundo: EMBRAPACNPT, 1995. 223 p.

SOUSA; D.M.G.; LOBATO, E. Correção de acidez do solo. In: SOUSA, D.M.G. de; LOBATO, E. (Ed.). Cerrado: correção do solo e adubação. Brasília: Embrapa Cerrados, 2002. p.81-96.

v. 36, n. 5, p. 1435-1442, 2007.

VIEIRA. L. Produção de minhocas em dejetos suínos estabilizados e valor nutritivo da farinha de minhoca para suínos. 1997, 56p. Dissertação (Mestrado em Zootecnia), Universidade Federal de Viçosa, Viçosa. 1997. 